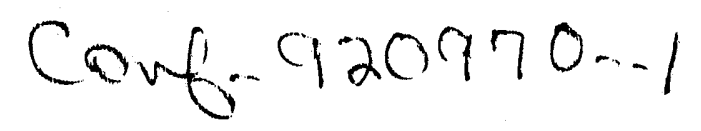

\title{
EXPERIMENTAL STUDIES OF CASCADE PHENOMENA IN METALS*
}

\author{
M. L. Jenkins', M. A. Kirk ${ }^{2}$ and W. J. Phythian ${ }^{3}$
}

${ }^{1}$ Department of Materials, University of Oxford, OX1 3PH, UK

${ }^{2}$ Materials Science Division, Argonne National Laboratory, Argonne, IL 60439

3Radiation Damage Department, AEA Technology, Harwell Laboratory, OX11 ORA, UK

ANU/CP- 76480

DE92 019586

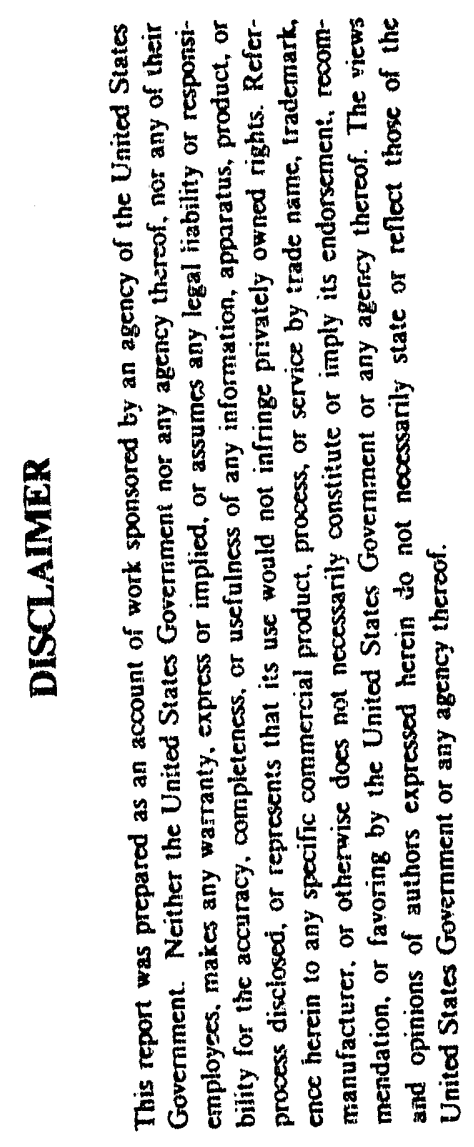

June 1992

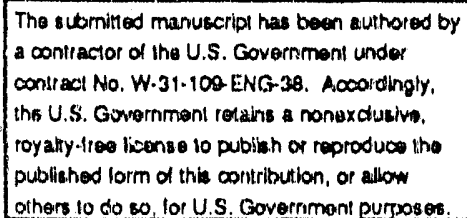

newion by

A $1602: 190$

INVITED paper to the International Conference on "Evolution of Microstructure in Metals During Irradiation", September 29-October 2, 1992, Ontario, Canada.

*Work supported in part by the U. S. Department of Energy, BES-Materials Sciences, under Contract W-31-109-Eng-38 (MAK) and by the corporate research program of AEA Technology under grant \# ABR 40029 (WJP).

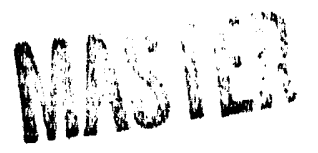




\author{
EXPERIMENTAL STUDIES OF CASCADE \\ PEENOMENA IN METALS \\ $M I$ Jenkins and $M A$ Kirk $^{2}$
}

Department of Materials, University of Oxford, OX1 325 anc W J Phytinian Radiation Damage Department, AEA Technology,
Harwell Laboratorl, OXIl ORA

We review recent ion-irradiation experiments which have been perzormed to investigate the collapse of displacement cascades to dislocation lcces in a range of metals and dilcys. Many of the results inclucing the cepercencies of the collapse probabilities on irradiation temperature, and ion dose, erergy and mass, can be explained witiin the framewcrk of a themal spike/iascade melting model which has been suggested by computer molecular cynemics simulations. Other aspects, such as the dependence of collapse prciabilities on the crystal structure and the effects of alloying and impurities, are less well understood.

\title{
1. INARODUCTICN
}

Under fast neutron irradiation of metals the majority of pointdefects are created within cisplacement cascades initiated by primary knock-ons of energy >jkev. The subsequent fate of these point-defects is crucial for most microstructural changes incuced by the irradiation, such as growth, ereep and siveling, segregation and precipitation, and alloy mixing and enianced diffusion. Cascades are inportant also in ion-beam mixing ancion implantation. For these reascns cascade phencmena have been extensively researched over the fast thres decades. A common and successful aporcach to study the vacancy component of the damage has been to examine in the transmission electron microscope thin foils which have typically been irradiated with low doses (s $10^{16} i o n s \mathrm{~m}^{-2}$ ) of heavy ions with energies in the range 10-100 $\mathrm{keV}$. The ions simulate the primary knock-ons produced in neutron irradiations. Vacancy lcops produced at individual cascade sites by "cascade collapse" are imaged, and information ostained on thoir morinology, sizes and number densities. The irradiation conditions - the type and energy of the ions, the dose and dose rate, and the irradiation temperature - can be closely controlled and allow the materials and irradiation parameters affecting cascade collapse to be explored. The efficacy of cascace collasse is usually cescribed guantitatively by tivo farameters, the cesest yield $Y$ and the cascade efficiency $\varepsilon$. $V$ is defined as $Y=N_{-}-N_{c}$ where $N_{x}{ }^{*}$ is the number of visible vacancy locps per unit area

Ion leave from the Materials Science Division, Argonne National Laboratory, Argonne, ILo0 439 
and $N_{c}$ is the ion dose, ie the number of cascades generated per unit area. Y therefore measures the proportion of cascades which collapse to visible loops. The cascade efficiency $\varepsilon$ is given by $\mathrm{N}_{v}$ (obs)/N $\mathrm{N}_{v}$ (th) where $\mathrm{N}_{w}$ (obs) is the number of vacancies retained in a loop of average area and $N_{v}(t h)$ is the calculated number of vacancies generated in the cascade. Absolute values of $Y$ and $\varepsilon$ should be treated with caution, particularly in comparing the results of different workers, because of different locp imaging, counting and measuring procedures, the necessity in scme cases to make allowance for loss of glissile locps to the foil surface, ion dose errors, and assumptions made in estimating $\mathrm{N}_{\mathrm{v}}$. However they are useful for identifying general trends.

In this revier we shall concentrate largely on recent progress in understanding cascade mechanisms made using this aporoach. We take as a starting point the review by English and Jenkins [1]. The position at the time of this earlier revien can be summarised as follows.

(i) Cascace collapse had been observed in rocm-temperature heavyion irradiations in a variety of purs materials (eg Cu [2-3], Ag[ 4-5], Au [6], Ni [7-9], Mo [1], Fe [10], W [11], Co [12], Rú [13], $\left.\mathrm{Cu}_{3} \mathrm{Au}[14-16]\right)$. It had teen found that in most fco metals collapse is eficient with high values of $Y$ and $\varepsilon$. In bco metals the defect vields and cascade ejziciencies aze on averace lower for equivalent irradiation conditions even afzer corrections due to loop loss to the surfaces in these materials. Insufficient research had been carried out in hop metals to be sure of trends although in the experiments which had been performed the yields were low. In general, the defect yield increased and the cascade efficiency decreased with increasing ion energy. Quantitative data extracted from refs [2-13] lilustrating these trends are shown in table I of ref[1] which has been published again as table III in ref? 17 ].

(ii) The cascade deposited energy density and the related vacancy supersaturation at the end of the displacement phase had been proposed as important parameters in determining collapse probabilities. This was deduced from the observation of increasing values of defect yield $y$ with increasing ion mass at constant ion energy as well as systematic experiments using molecular-ion irradiations (see table II of ref (1]).

(iii) Usually faulted locps nucleate on close-packed planes; these may subsequently uniault to perfect loops, although in fcc metals partial or complete dissociation to stacking-fault tetrahedra is also possible [4]. Generally the majority of locps were of the types expected on the critericn of lowest elastic strain energy. Howerer less energetically favoured types wera found in high energy-density cascades in $F=[10]$ and Mo [1] ( b $=a\langle 100\rangle$ rather than $\underline{\underline{b}}=a / 2\langle 110\rangle$ ) and in Ru [11], where the p:opcrtion of $c-$ component loops to the expected faulted and

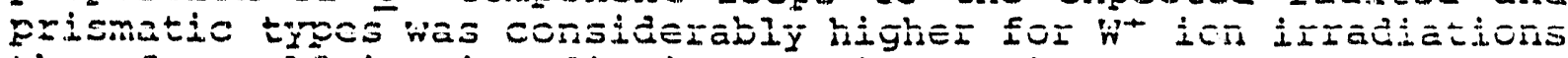
than for self-ion irradiations. This was incerpreted as another energl density effect. 
(iv) Cascade collapse was found to occur at low ( $30 \mathrm{~K}$ ) irradiation temperatures in a number of materials (Cu,Au [16], Cu, Ni, Fe [8]). Since at this temperature no thermal migration of vacancies is possible, this was taken as evidence that the collapse process is athermal and probably occurs in the thermal spike phase of the cascade. The collapse probabilities however were considerably smaller at $30 \mathrm{~K}$ than at rocm temperature, although the data for materials other than $C_{3}$ Au were limited. In $\mathrm{Cu}_{3} \mathrm{Au}$ no further collapse occurred on warming to room temperature.

(v) In elevated temperature irradiations measured defect yields (a.ter cooling to room temperature) in $\mathrm{Cu}, \mathrm{Ni}$ and Mo decreased $[18,7,19]$. In $\mathrm{Cu}$ and $\mathrm{Ni}$ the decrease was abrupt above a certain threshold temperature ( for $\mathrm{Cu}, 500 \mathrm{~K}$ and for $\mathrm{Ni}, 750 \mathrm{~K}$ ). This can be accounted for by an athermal cascade collapse process followed by loop shrinkage due to thermal emission of vacancies. In Mo, by contrast, vacancy loop numbers in self-ion irradiations decreased more gradualiy at temperatures 420-470 $\mathrm{K}$ which are too low for thermal emission of vacancies in this material. In irradiations with $\mathrm{Xe}^{-}$ions however no fall-off in defect yields were found at temperatures up to $670 \mathrm{~K}$ [1]. These results suggests that the collapse procability in Mo is itself temperature dependent and again highlight the role of the cascace energy censity.

(vi) Rather limited data existed on the influence of alloying and impurities on the collapse process (ses table IV of reti17] for a summary) and the results which had been reported did not seem open to simple explanations. In copper alloys, stathopoulos et al [20] found that the defect yields increased with alloying in all cases, irrespective of the strength of the solute-pointdefect binding. A correlation between the magnitude of the solute-atom size factor and the increase in defect yield led these authors to suggest that the dominant factor in determining this trend was dechannelling of incident ions and channelled knock-ons. This however could not be established with confidence, and the explanation does not seem entirely consistent with the trends seen at higher ion energy [20]. The situation with interstitial impurities was even less clear. very small quantities of $\mathrm{N}$ in Mo appeared to have a cramatic effect on the yield although no really plausible explanation of why could be of Eered[19]. Yields were also generally low in stainless steels compared with base alloys, but again this was not well understood $[7,21]$.

English and Jenkins [1] discussed the results summarised atcve in terms of cascade models current at that time. They concluded that defect migration occurring during thermal spikes and the rate of cocling of the spike region were central to an understanding of the collapse process. They suggested also that ine initial vacancy configuration and concentration were important parameters controlling loop for nation. They postulated the existence in bcc and hop metals ci a barrier to loop 
nucleation possibly determined in part by the stacking-fault energy. Over the past five years several experiments have been carried out in order to explore these ideas further and to resolve some of the outstanding issues. These experiments are described in section 3 below.

First however it is appropiate to describe briefly the advances in cascade simulations made in the last five years which have considerably changed our perception of cascade processes and provide a framework for much of the interpretation of recent results.

\section{Recent advances in computer simulations of cascades}

Computer simulation experiments have advanced considerably in recent years with not only better hardware but also more realistic simulations. These have been reviewed recently by de la Rubia and Phythian [22] and Guinan [23]

The largest activi.ty in the area of cascade simulations has been with the use of molecular dynamics. A large proportion of the work has been conducted for "Cu", and to a lesser extent "Ni" and "Fe"[24-32]. known work is currently underway on "Ti", "קg", "Au" and alloys such as "Ni-AI" and "Cu-Au". We put "Cu" and "Ni" eta in quotation marks here to remind us that these are simulations, and the cetailed processes found may well depend on the choice of potentials and other computational details. To date, the highest primary knock-on energy simulated is one $25 \mathrm{keV}$ event, although many cascades of energy $10 \mathrm{kev}$ and below have been examined. With these low energies (by experimental standards) and the differences in detail brought about by simulation methods etc. a degree of caution should be used in comparing data; however, the simulations do provide interesting insight into what may be hapening in reality.

In the context of this review, the most important observation of the computer simulations was the identification that local 'melting' of the cascade core had occurred. This was achieved by comparison of the densities, temperatures and pair-correlation functions with the corresponding quantities in the liquid phase [24]. In this simulation of "Cu", the local melting persisted for several picoseconds, a time long enough for several lattice vibrations to occur and for vacarcies located within the melt to lose their individual identities. At this stage the vacancies were represented as a generally lower density within the melt, typically - $85 \%$ that of crystalline "cu". As the cascade melt cooled it was observed to recrystallised coherently at the cooler peripheries. As recrystallisation proceeded density fluctuations within the melt increased and eventually "froze out" as vacancies. The final numier of vacancies was dependent on the number of replacement collision sequerces extending beyond the melt boundaries whilst their final configuration depended cr the speed of the solidification front. The sweeping of vacancies into the cascade centre by this process is similar to zone refining. These earlier simulations with pair potentials have 
since been repeated with more sophisticated many body potentials that show essentially the same conclusion that a liquid like cascade core does exist with a density $20 \%$ that of a liquid at similar temperature [32]. However, no well defined solidification front has been observed in the simulations with $E \leq 5 \mathrm{keV}[29,22]$

A further question which has been addressed by molecular dynamics is the mechanism whereby vacancies and interstitials are separated in the cascade. All the simulations have concluded that replacement collision sequences do play a role in the separation process, but the degree is temperature sensitive. In studies of cascades conducted at $100 \mathrm{~K}$ the numbers and average lengths are smali [32]: eg, in $2 \mathrm{keV}$ cascades in "Cu" an average of about 7 focussons and replacement collision sequences, the latter of average length $6 \pm 2$ replacements, were emitted per cascade. They were responsible for transporting only a small fraction, $2 \%$, of the total cascade energy. The short average lengths of collision sequences is consistent with experiments by kirk et al [33] and Eullough et al [34]. Kirk et al [33] for example found a very low fraction of $\langle 110\rangle$ replacement events extending away from the average neutron cascade $(30 \mathrm{keV}$ recoil event) in $\mathrm{Ni}_{3} \mathrm{Mn}$ at $5 \mathrm{~K}$. No more than $4 \%$ of the total replacements in the average cascade could be placed into these replacement collision sequences, indicating that the spatial distribution of interstitials is rather compact around the dezect cascade. This result, however, does not reveal the extent of focussons emanating from the defect cascade because they do not produce replacements.

In $\mathrm{OK}$ and $4 \mathrm{~K}$ simulations, using a simpler pair potential [24], replacement collision sequences play a more significant role, with typical lengths of 20 replacements. An interesting feature of all simulations is the very narrow time window towards the end of the displacement phase when the collision sequences appear, suggesting that their propagation is very sensitive to the conditions pertaining at the cascade peripheries, and these conditions may be satisfied for only a short time.

A second mechanism, that of "ballistic clustering" was found to be increasingly important in "Cu" as the cascade energy increased [29]. In this mechenism ballistic ejection of interstitials from the cascade core was followed by interstitial clustering at the cascade periphery. These small interstitial clusters invariably had Burgers vectors tangential to the cascade periphery allowing them to escape from the cascade region by thermally-assisted glide. This mechanism was considered to be critical in preventing reccmbination and so enhancing vacancy survival. A. higher-energy manifestation of this process has been cbserved by de la Rubia and Guinan in the highest energl cascade so far simulated [28]. Here the high compressive forces generated in the collisional phase lead to the punching of a 17 interstitial atom platelet from the cascade periphery.

The mechanisms cescribed above lead to rediced recombination at the cascade core. If these same phenomena hold true for cascades 
generated experimentally with higher energy, one could expect an increase in vacancy 100 p production. It should however be noted that of all the simulations conducted to date, very little evidence for vacancy loop production has been reported. The formation of a vacancy 100 p has however been followed with molecular dynamics by creating areas of high vacancy concentration, and following the subsequent motion at high temperature [eg 35,36$]$.

\section{Recent experimental studies}

Most of the experiments reported in the last few years have besn designed to explore systematicaliy the parameters identified as controlling cascade collapse. For convenience we shall consider first experiments in pure metals, then in alloys.

\section{1 pure metals}

Selected values of defect yields and cascace efficiencies for recent experiments in pure metals are shown in table 1.

\subsubsection{Face-centred cubic metals}

Several studies have been published in the past few years, with particular emphasis on $\mathrm{Ni}$ and $\mathrm{Au}$ and on the use of in-situ irradiations and observations.

Nickel and copoer Robertson et al [37] completed their detailed study of cascade collapse in $\mathrm{Ni}$ following irradiation with 50 and $100 \mathrm{keV} \mathrm{Ni}^{-}$and $50 \mathrm{keV} \mathrm{Kr} \mathrm{Kr}^{+}$ions in the FVEM-Acceleratcr Facility at Argonne National Laboratory. Vacancy loop formation was followed as a function of both the irradiation temperature ( $30 \mathrm{~K}$ and room-temperature) and irradiation dose $\left(10^{15}-10^{17}\right.$ ions $\left.\mathrm{m}^{-2}\right)$. The major conclusions were as follows:

(i) Dislocation loops were produced in the low-temperature irradiations but the probability of collapse at $30 \mathrm{~K}$ was only about half of the room-temperature value (see table 1 ). These oiservations are consistent with previous experiments in $\mathrm{Cu}_{3} \mathrm{Au}$ [16] and the preliminary results in $\mathrm{Cu}, \mathrm{Fe}$ and $\mathrm{Ni}$ [8] which were reviewed by English and Jenkins [1]. Vacancy locp formation at temperatures where the vacancies are immobile implies a thermalspike mechanism of collapse. Lower yields at $30 \mathrm{~K}$ were als $)$ found in the earlier experiments and attributed to more effective quenching of the thermal spike.

(ii) A new population of loops appeared when foils irradiated at $30 \mathrm{~K}$ were subseguently warmed to rocm temperature. This ne'w observation was attributed to a population of sub-microscopic clusters which grow to a visible size when there is at least inited vacancy mobility. It is interesting to note that new loops do not form at $30 \mathrm{~K}$ under the influence of the electron beam 
(by a mechanism of radiation-induced migration) in any of the materials so far studied.

(iii) At cascade overlap doses a new phenomenon of "cascade dissolution" was observed. With successive incremental doses a fraction of the loops disappeared (fig.1). Others changed their positions or their Burgers vectors or appeared to coalesce with neighbouring loops. Similar effects have been seen in Cu[38] and Ni-1\%Al[39,40]. They were believed to originate in existing loops being engulfed by new cascades. The plausibility of this is demonstrated by recent computer molecular dynamics simulations of Foreman and co-workers $[41,42]$, such as the example shown in fig. 2 where a pre-existing vacancy loop is effectively annihilated by the new cascade event. In other simulations, not shown, new loops reformed at the cascade site. These annihilation/reformation effects are capable of explaining the trend of decreasing defect yield with increasing dose found in the experiments.

(iv) Defect yield values (table 1) were confirmed to be lower than for $\mathrm{Cu}$ irradiated under similar conditions.

Gold Jäger and Merkle[43] and Calder et al[44] have examined energy-density ejfects by studying loop formation procuced by low-energy ions: Jäger and Merkie employed 10-20 keV Bi+ anc 20-

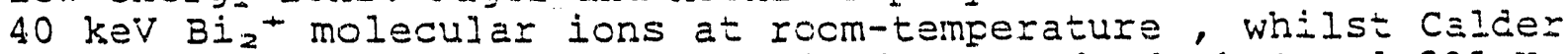
et al irradiated with $5-20 \mathrm{keV} \mathrm{Bi-} \mathrm{ions} \mathrm{at} \mathrm{both} 4 \mathrm{~K}$ and $285 \mathrm{~K}$. These low-energy irradiations result in very compact cascaces of high energy density close to the foil surface. The latter authors compared their results with self-ion irradiations of Cu of the same total energy but an order of magnitude lower energy density.

Jäger and Merkle concluded that there was a higher probability for loop formation and a more efficient vacancy-interstitial. separation in dense cascades. It is interesting to note however that the defect yields for $20 \mathrm{keV}$ monatonic $\mathrm{Bi}^{+}$and diatomic $\mathrm{Ei} \mathrm{.}_{2}^{+}$ ions, ie the same total energy, were in fact very similar (table 1). It was only when cascades were compared on an energy per atom basis that significant differences in yield were seen. Molecular ions are expected to dissociate on impact and produce strongly overlapping cascades with enhanced energy densities and vacancy concentrations compared with single ions of the same total energy. In $\mathrm{Sb}^{+}$molecular-ion irradiations of Mo (see English and Jenkins[1], table II) the defect yield increased with the numier of atoms in the ion at the same total energy indicating a stronger energy density effect than seen in Jäger and Merkle's experiments in Au.

A relatively weak energy-density effect was also found in Calder et al's experiments. Their cata for $10 \mathrm{keV}$ ions (table 1) shcwed that the defect yielcs for $\mathrm{Bi}^{+} \rightarrow \mathrm{Au}^{-}$and $\mathrm{Cu}^{+} \rightarrow \mathrm{Cu}$ were very similar at both $4 \mathrm{~K}$ and $285 \mathrm{~K}$ despite the markedly different energy densities. As in other experiments, the yields at $4 \mathrm{~K}$ were lower than at room temperature. The cascade efficiency $\varepsilon$ was 
however larger in Au than in copper. In Au the efficiency was higher at $4 \mathrm{~K}$ than at $285 \mathrm{~K}$ whilst in Cu this trend was reversed.

Elevated temperature irradiations of AU, Cu and Ni sekimura et al [45] have performed in-situ $\mathrm{Xe}^{+}$ion irradiations of au at elevatud temperatures up to $770 \mathrm{~K}$ using a $400 \mathrm{kV}$ ion-accelerator linked to a $200 \mathrm{kV}$ TEM. Vacancy loops and stacking-fault tetrahedra were observed to form during irradiation, and then shrank and disappeared, consistent with the model based on athermal collapse and thermal shrinkage by vacancy emission deduced from the ex-situ experiments on $\mathrm{Cu}$ and $\mathrm{Ni}$ described in section 1. The lifetimes of the defects under irradiation were however much shorter than under isothermal annealing at the same temperature without irradiation and were strongly dependent on the ion dose rate (which was varied from $1.3 \times 10^{2 \frac{1}{3}}$ to $1.3 \times 10^{1.5}$ ions $\left.\mathrm{m}^{-2} \mathrm{~s}^{-1}\right)$. At $470 \mathrm{~K}$, when vacancy clusters are thermally stable, loops were still seen to shrink in a step-like manner. These observations suggest that interstitials produced in subsequent nearby cascades play a role in the loop annihilation process. Cascade overlap effects such as sudden size increases of vacancy loops, and a tendency to larger loop sizes at highe: cose rates were also identified. Sub-cascade formation was found to be less likely at higher irraciation temperatures.

Sakaida et al, [46] have performed in-situ $400 \mathrm{kev} \mathrm{Xe}^{+}$ irradiations of $\mathrm{Ni}$ and $\mathrm{Cu}$ at elevated temperatures $670-770 \mathrm{~K}$. Using video techniques, two defect lifetimes were ciserved in thicker foil, which they suggested was due to populations of both vacancy and interstitial loops. They suggest the longer lifetime component, virtualiy stable at $770 \mathrm{~K}$, was due to interstitial loops. This analysis is in disagreement with several other experiments in $\mathrm{Ni}$, eg [7]. A possible alternative possibility is that the different vacancy cluster morphologies expected to be present- Frank loops and stacking-fault tetrahedra- have different stabilities. The question of interstitial loop formation at individual cascade sites is discussed in section 4.

Aluminium Results of Bui [47] et al in Al are shown in table 3 and are discussed briefly in section 3.2 .4 below. In this light metal the yields are very low.

\subsubsection{Body-centred cubic metals}

Iron Early experiments in $E$ e had estailished that cascade collapse does not occur under self-ion irradiation to low doses, <1018 ions $\mathrm{m}^{-2}$ [10]. Kirk and co-workers [8,39] have shown however that collapse does take place at high overlap doses $\left(>10^{29}\right.$ ions $\left.\mathrm{m}^{-2}\right)$. The yield is very low $(\sim 0.001)$ for both $50 \mathrm{keV}$ and 1nokey self-inn irradiations (tanle 1). No difference in Yield between irraciations at $30 \mathrm{~K}$ and $300 \mathrm{~K}$ could be detected. 
Comparisons of loop production as a function of dose in $\mathrm{Fe}$, $\mathrm{Ni}$ and $\mathrm{Cu}$ at $300 \mathrm{~K}$ and $\mathrm{in} \mathrm{Fe}$ and $\mathrm{Ni}$ at $30 \mathrm{~K}$ are shown in figs. 3 and 4 respectively. The linear behaviour with $\mathrm{n}=1$ seen for $\mathrm{Cu}$ and $\mathrm{Ni}$ at $300 \mathrm{~K}$ and $\mathrm{Ni}$ at $30 \mathrm{~K}$ indicates a loop production rate within individual cascades which is constant with dose at low doses. The deviation of the slopes towards $n<1$ at high doses in $\mathrm{Cu}$ and $\mathrm{NI}$ is due to overlap effects such as loop coalescence, see section 3.1.1. The slope of $n=0.7$ in $F e$ at $300 \mathrm{~K}$ ( $\mathrm{fig.3}$ ) may also be due to saturation type behaviour. The slope of $n=1.5$ in Fe at $30 \mathrm{~K}$ (Eig.4) may be the net result of a low probability for isolated cascade collapse $(n=1)$ combined with a quadratic loop production rate $(n=2)$ expected from simple overlap of two cascades resulting in one dislocation 100p.

Vanadium preliminary results on cascade collapse in vanadium under $80 \mathrm{keV} \mathrm{W}^{+}$ion-irradiation at room temperature have been reporter by Phythian et al [48]. A population of small vacancy loops of edge character, with $\underline{b}=1 / 2<111\rangle$ was produced. The defect $y$ ield and cascade efficiency values of $Y=0.115 \pm 0.01$ and $\varepsilon=0.20 \pm 0.05$ respectively are comparible with other bcc metals.

\subsubsection{Hexagunal metals}

Preliminary results by Phythian and co-workers on cascade collapse in Ru were reviewed by English and Jenkins [1]. This group has now completed a sustematic investigation of cascade collapse at room temperature in a range of hexagonal metals $[13,49,50]$. In Ru $[13,49]$ irradiations were performed under a wide range of irradiation conditions (ion energies from 10 to 100 $\mathrm{keV}$ and ion masses from $84\left(\mathrm{Kr}^{+}\right)$to $\left.184\left(\mathrm{~W}^{+}\right)\right)$. A Eurther series of comparative experiments was carried out in $\mathrm{Ti}, \mathrm{CO}, \mathrm{Re}, \mathrm{Ru}$ and $\mathrm{Mg}$, chosen to encompass a wide range of materials properties, using $\mathrm{sb}^{+}$ions of energy $100 \mathrm{keV}$ and $150 \mathrm{keV}$ [50]. The main results were:

(i) Vacancy dislocation loops were found in all cases except for $100 \mathrm{keV} \mathrm{Sb}^{+} \rightarrow \mathrm{Mg}$. For irradiation directions close to [0001] the predominant defect geometries were prism loops. Cascades collapsed initially onto $\{1010\}$ planes to form loops with Burgers vectors $1 / 2\langle 1010\rangle$ some of which subsequently unfaulted to form perfect $1 / 3\langle 1120\rangle$ type loops. In Ru, for beam directions in the basal plane, a smali minority of loops collapsed onto the basal planes to form faulted $b=1 / 2[0001]$ locps which can transform to lower energy faulted loops with $\underline{b}=1 / 6\langle 20 \overline{2} 3\rangle$.

(ii) The defect yields Y varied widely from material to material. cascade efficiencies were less variable (table 1). Within a given metal the yield $Y$ and efficiency $\varepsilon$ values showed similar trends to cubic metals; these values were comparable with those found in bcc metals and in general were lower than in foc metals.

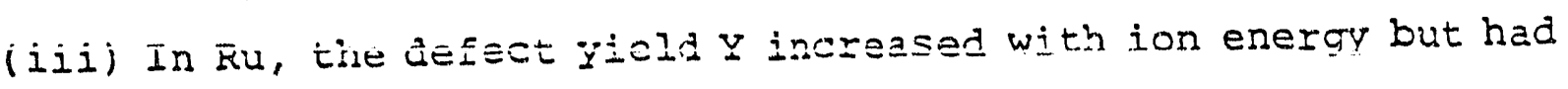


a complex dependence on ion mass. At $50 \mathrm{kV}$ or lower the yield increased with increasing ion mass; at $100 \mathrm{kV}$ this trend was reversed (Eig.5).

This last result is at first puzzling but may be understood in terms of the formation and spatial arrangement of sub-cascades at higher cascade energies. Attempts however to correlate the overall materials trencis with obvious materials parameters ( the c/a ratio, stacking-fault energy, atomic mass and melting temperature) were not successful. The authors concluded that the complex behaviour could be controlled by many parameters, with interpretation made more difficult by phase changes in Ti and $\mathrm{Co}$.

Results of Yellen et al [51] on two different purities of Ti are shown in table 3 and are described briefly in section 3.2 .5 below.

\subsection{Alloys}

Recent experiments on alloys have fallen into two categories, with separate objectives. In the first type of experiment alloys such as $\mathrm{Cu}-\mathrm{Ni}$ are chosen which exhibit complete solute solubility over the entire composition range. Since the atomic masses of the constituents are similar, the cascade energr density remains almost constant in alloys of di.jeerent comecsition. The meling temperature varies with compositicn. This enables the role $c$ E this parameter (which is suggested by cascade simulations to be important, see below) to be explored. In the second tyce of experiment the affect of dilute alloying or impurity elements on the collapse process is of interest.

\subsection{1 $\mathrm{Cu}-\mathrm{Ni}$ and Ag-Pd alloys.}

The experiments of Smalinskas et al [52] fall into the first of the above categories and are described in detail in another paper in this issue. In summary, Smalinskas et al found that vacancy $100 p$ production rates and vacancy retention in the Ag-Pd alloys scaled with melting temperature over the whole range of compositions: the higher the melting temperature the lower the defect yield and cascade efficiency. In the $\mathrm{C}: \mathrm{l}-\mathrm{Ni}$ alloys the defect yield also decreased as the melting temperature increased in the range $\mathrm{Cu}-30 \% \mathrm{Ni}$ to $\mathrm{Cu} 70 \% \mathrm{Ni}$. These trends are in agreement with the predictions of computer simulations, as discussed in section 4. However in the Cu-Ni system the behaviour for small (< $30 \%$ ) or high $\mathrm{Ni}$ contents was more complex and was not defendent on melting temperature.

\subsubsection{Dilute $\mathrm{Ni}$ alloys}

The experiments of Vetrano et al $[40 ; 53]$ fall into the second category and are also described in another paper in this issue. These authors explored the effect on cascade collypse of small 
additions of $\mathrm{Si}(0.6 \%$ and $4 \%$ ) and $\mathrm{AI}(0.5 \%, 5 \%$ and $7 \%$ ) to nickel. Irradiations were with $50 \mathrm{keV} \mathrm{Kr}^{+}$ions at rocm-temperature and at $30 \mathrm{~K}$. The presence of these substitutional alloying elements was found to affect strongly the collapse probabilities and loop sizes. At $30 \mathrm{~K}$ the defect yield showed an initial increase followed by a decrease with increasing solute content. Experiments at $300 \mathrm{~K}$ showed the same trends (table 2). Mean locp sizes were measured only in the room-temperature ex-situ experiments and showed the loops to be larger in the more concentrated alloys. The yields were considerably lower at $30 \mathrm{~K}$ than for the corresponding alloy at $300 \mathrm{~K}$. The trends with alloying additions should be compared with the results of stathopoulos et al [20] on dilute cu alloys where again complex effects were seen (see section 1). Vetrano et al explain their results by invoking various impurity-caused changes to botil the collisional and thermal-spike phases of the cascade. The specific mechanisms considered included defocussing of focusons by impurities to change the energy density profile of the cascade and interstitial trapping to reduce recombination curing the thermal-spike phase.

\subsubsection{Fe-Ni-Cr alloys}

Tappin [54] has examined cascade collapse in a number cf hignpurity Fe-Ni...Cr alloys of varying Ni content (15-70ato). The $\mathrm{Cr}$ content was held constant at $13 a t \%$. Irradiations were a = icti low- and room-temperature with low-energy $\mathrm{Bi}^{+}$and $80 \mathrm{KeV} \mathrm{Au}^{+}$, $\mathrm{W}^{+}$or $\mathrm{Xe}^{+}$ions. Some defect yield and cascade efficiency values for the 15at\%Fel5at\%Cr70at\%Ni alloy are shown in table 2 (ses also ref[55]). They show trends with temperature and ion mass similar to pure materials. The more interesting aspect of this work- the dependence on the $\mathrm{Ni}$ content - has not yet been fully analysed.

\section{2 .4 Al-H alloys}

Buj. et al [47] have investigated the effect of small quantities of hydrogen ( 900 and $1300 \mathrm{appm}$ ) on cascade collapse in Al under $50 \mathrm{keV} \mathrm{Kr}^{+}$ion irradiation. The results are shown in table 3 . The presence of the hydrogen was found to decrease the defect yield markedly, although loop sizes and geometries were unaffected. It was speculated that the effect is due to the formation of hydrogen-vacancy complexes during the lifetime of the cascade.

\section{$3.2 .5 \mathrm{Ti}$ of different purities}

Yellen et al [51] examined Ti of two purities, a high-purity iodide material containing $300 \mathrm{ppm}$ oxygen, $30 \mathrm{ppm} \mathrm{C}$, with <10ppm of other impurities, and a less pure commercial material containing 1100 pom rrygen, $600 \mathrm{ptm}$ C, $500 \mathrm{prm}$ Al, plus smaller quantiles of oth urities. Irradiations were with. $S b, S_{2}$, and $\mathrm{Sb}_{3}$ ions of energy $50-150 \mathrm{keV}$. The results are also shown in table 3 . In contrast to Bui et al's results, yialds were scmewid 
higher fox the less pure material. Other trenas were as expected.

\section{Discussion}

Attempts have been made to interpret most of the experiments described above in terms of mechanisms seen in molecular dynamics simulations. The "cascade melting" modei in partzcular has several attractive features which suggest that it might occur in actual materials, and so has been invoked to explain several of the trends fould in the experiments descrited in sections 1 and 3:

(i) It can explain the large differences in defect yielcs and cascade efticiencies between materiais such as $\mathrm{Cu}$ and Ni which have similar structures and atomic weights and where the ballistic phases of cascades are therefore similer. In the simulations for "Ni" the solidification front moved much more rapidiy than in "Cu" as a result of its higher melting temperature and this led to less effective siweping of vacancies into the cascade centre [24].

(1i) It provides a mechanism for athermal cascade collapsa at low temperatures. The lower yields found at low temperatures are then explained as a conseguence of the more rapid cuencing of the thermal spike cue to the larger temperature gracients. T:Ls has been shown explicitly in simulations [27].

(iii) It provices a ratural mechanism for the very effective disordering found at the cores of cascade sites in orcered alloys such as $\mathrm{Cu}_{3} \mathrm{Au}$. In their study of cascades in $\mathrm{Cu}_{3} \mathrm{~A}_{2}$ produced by $\mathrm{Cu}^{+}$ions Jenkins and Wilkens [14] estimated that the ratio of replacements to displacements is at least 10 and could te far higher. A large ratio is easily explained by local melting followed by recystalisation at a rate too fast to allow reordering. Other mechanisms of dsordering may be operating at the cascade peripheries however.

(iv) Enwrgy censity effects are also explained naturally. In general more efficient vacancy clustering would be expected in more compact cascades as is usually observed. Molten zones would be less likely to form in the more diffuse cascades in light materials such as $A 1, M g$ and $T i$, and this is consistent with the low yields 1 in these materials. The xather weak cegendence ol defect yields on tie energy density in very compact high energydensity cascades in Au described in section 3.1 .2 may bi: understood as a conseruence of the size of the molten regior: exceeding the 1nitial cascade volume. In this case the size of the moltea region is governed by the total cascade energl. Rather direct evidence for this was presented by Jenkins and Eaglish [15] for high esergl-density cascades in cupdu groduced by molecular Sb lons where trie size of discrdered zores was

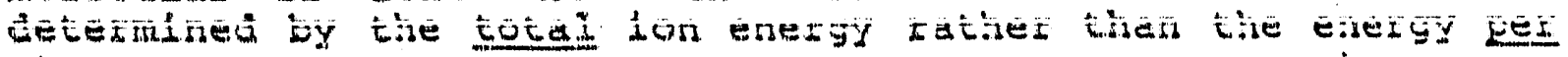
atom. 
(v) The model may be capable of explaining at least qualitatuively some of the impurity/al]oying effects. Vetrano et al $[40,53]$ have argued that disruption of focusson chains by impurity atoms will reduce the effective cascade volume leading to an increase in the extended cascade energy density. The resulting increase in temperature of the material immediately surrounding the molten zone decreases the solidification rabe and so increases the effecciveness of the vacency sweeping mechanism. In discussing the plausibility of this mechanism vetrano et al assumed fairly arbitrarily an average focusson length of 30 atom chains. In current molecular dinamics simulations (which are however for much lniver energy cascaces) focussons apcear to play a ratiner minor role and their average rengths are much shorter, so this mechanism must be treated with some caution.

(vi) Cascade overlap effects - annihilation of existing loops, loops apparently changing Burgers vectors, loop coalescence- are explained naturally. Locp dissolution is to be expected if an existing loop is engulfed by the molten zone of a new cascade $[38]$.

(vii) Cascade melting also explafins well the differences in atomic mixing tetiveen $\mathrm{Cu}$ and $\mathrm{Ni}$ which are observed experimentaliy $[56]$.

The cascade melting model suggests that the melting temperature may be an important parameter in determining cascade collapse, and this is consistent with the experiments of smalinskas et al. [52]. This effect may have been exaggerated in the simulations because the potentials used predict a bigger difference in melting temperature than is $t n$ fact the case. In practice also, another effect not included in the simulations may be important. This is energy tranfer to the electronic system, via electronphonon coupling, which can lead to effective "quenching" of the thermal spike. This has been the subject of some thcoretical attention over the past few years $[57-60]$ Flynn and Averbach [57] developed a mcdel for treating ion-electron interactions in cascades and demonstrated that the effects could be significant. Calculations based on this model by finnis et al and caro and Victoria $[59,60]$ found large differences in the cooling rates of casuades for different strengths of electron-phonci coupling. Cascades in Ni quench more rapidly because of the mone effective coupling due to the higher censity of states at the kermi level. When the coupling was incorporated into molecular dynamics simulations the net effect was to inhibit defect production in low-energy cascades (fig 6 ). In the $\mathrm{Cu}-\mathrm{Ni}$ alloy experiments the fact that the yield does not follow the melting temperature at high Ni content suggests that electron-phonon coupling may be playing a role.

Despite the success cf the cascade molecular dynamics simulaticns in explaining many of the chserved trends. it would be wrong at this point to place total reliance on their applicability. The "cascade melting" model is eminently plausible but whether cascade melting is assciutely required to explain the 
experimental iesults is more debatable. As yet, several features of the resuitis are not well understood. These include the low defect yields in bcc and hop metals and the afiect of impurities. The two inay be related, because the yields are particulary low in materials where impurities, especially interstitial $0, \mathrm{~N}$, and $c$, are sign:ficantly more soluble, suggesting that these impurities may play an important role in governing point-cefect survival and cascade collapse. It would be interesting to see if cascade simulations specifically aimed at these problems would support any of the mechanisms put for'vard to account for these affects. Also valuable would be simulations to yet higher cascade energies to see if the collapse process can be followed to vacancy loop production.

It is perhaps valuable to compare the results of the cascade collapse studies using low-dose jon irradiations described above with certain recent results reported for 14 MeV neutron irradiations to low coses, especially at low temperatures with cryotransfer for TEM purposes. The latter experiments are comparable with the in-situ ion-irradiation studies, also at temperatures near $30 \mathrm{~K}$; note that in both cases the irraciations are of thin foils. Several differences can be noted. The neutron experiments find defect cluster or loop populations in thin foils of $A u$ and $C u$ at low temperatures $(24 \mathrm{~K})$, and no TEM visible defects in $\mathrm{N}$ - or A.I thin foils [61]. The nature cE the low-temperature cezects in Au and $C u$ was determined to be interstitial by tire $2.1 / 2 \mathrm{D}$ meticd. The compucer simularicrs described in section 2 do suggest that interstitial loop generation within indivicual cascades may be a possibility. However, we have been unatele to find any reported low-cose ionirradiaticn experiment which claims to find interstitial loces, except those which have employed the 2 1/2 D method [eg 62], and recent work by Fukusinima et al [63] which claims to confirm the accuracy oi the $21 / 2 \mathrm{D}$ method. These results which find interstitial loops in thin foils at low doses are in striking disagreement with earlier ceterminations of the locp nature using I-vector analysis (the black-white contrast change with cepth, measured by stereo-microscopy) applied by eg Häussermann [64], Wilson [65] and stathopoulos [2,25]. In all these cases and many others all defects have been found to be of vacancy type. In other cases, eg the work on $A g$ and $C u$ by Jenkins [4], the vacancy nature of the damage was evident frorn the gecmetry of the observed defects - which were all partially dissociated Frank loops or stacking-fault tetrahedra. Theoretical work of Gruschel and Wilkens (unfortunately only published in thesis form [66]) indicates that the $21 / 2$ technique In the case of stacking-fault tetrahedra in A.g this has been shown explicitly: tetrahedra identified as interstitial by the $21 / 2 \mathrm{D}$ method have been shown by other methcds to be vacancy $[67,68]$. This causes us to view results based on the $21 / 2 \bar{D}$ method with great caution. On the otiner hand both Ruault et al [62] and Fukushima et al [63] cherked their 2 1/2 D results against those obtaired from the l-vestor stereo method and report that both teohnigues gave identical Froportions of vacancy and interstitial loops. The question of whether interstitial loops are formed at individual cascade sites therefore remains 
controversial.

other differences found when comparing ion-cascade results with $14 \mathrm{MeV}$ neutrons include observations of loops in $\mathrm{Ni}$ under $50 \mathrm{keV}$ self-ion irradiation at $30 \mathrm{~K}[8,37]$, but not under $14 \mathrm{MeV}$ neutron irradiation [61]. Also, significant loop formation is observed under subthreshold electron irradiation in low-temperature neutron-irradiated $\mathrm{Au}, \mathrm{Cu}, \mathrm{Ni}$ and $\mathrm{Al}$, while similar effects have not been found in low-temperature ion-irradiated $\mathrm{Ni}$, even though the concentration of uncollapsed defect cascades is quite high in this case. We do not understand the reasons for these discrepancies.

As a final point we note that great care must be taken when employing the weak beam technique to defect microscopy. Robertson et al [37] found significant artikact contrast, which could easily be confused with defect contrast, in ion-irradiated $\mathrm{Ni}$, which was often associated with a weak diffuse ring in the diffraction pattern. This was believed to result from either surface contamination or oxide structure. Interestingly, Shimomura et al [61] found similar "defect" contrast in weak-beam conditions. "Defect" contrast was also seen when a portion of a weak ring pattern was used for imaging in dark field. We believe that the possibility that these "defects" are artifacts cannot be excluded.

\section{Conclusions}

We have reviewed several recent ion-irradiation experiments which add to our knowledge of cascade collapse effects in metals. New cascade overlap effects have been identified. It has been shown that the observed dependencies of the collapse probabilities on the irradiation temperature, the cascade energy density and the ion dose can be understood within the framework of a local cascade-melting model which has been suggested by molecular dynamics simulations. Further simulations are suggested to try to elucidate the role of alloying elements and impurities in the collapse process, which is presently poorly understocd. The formation of interstitial loops at individual cascade sites is still the subject of some controversy and further investigations would be worthwhile.

\section{Acknowledgements}

MAK is grateful for the award of an SERC Visiting Fellowship and WJP for the aivard of a Wolfson College Industrial Fellcwship. The work of WJP was funded by the corforate research programme of AaA TechnologI under grant \# ABR 40029. 


\section{References}

[1] C.A.English and M.I Jenkins, Mat.Sci.Forum 15-18 (1987) 1003 .

[2] A.Y.Stathopoulos, Phil.Mag. A44 (1981) 285.

[3] A.Y.Stathopoulos and C.A.English J.Nucl.Mat.108 \& 109 (1985) 9 .

[4] M.I.Jenkins, Phil.Mag. 29 (1974) 813.

[5] T.Schober, Phys.stat.sol.(a) 1 (1970) 307.

[6] K.I.Merkle, I.R.Singer and J.R.Wrobel, Appl.Phys.Lett. 17 (1970) 6 .

[7] T.M.Robinson and M.I.Jenkins, Phil.Mag. At3 (1981) 999.

[8] M.A.Kirk, I.M.Robertson, M.I.Jerkins, C.A.English, T.J.Flack and J.S.Vetrano, J.Nucl.Mat. 149 (1987) 21.

[9] K.Kitagawa, K.Yamakawa, H.Fukushima, T,Yoshiie, I.FaYashi., H.Yoshida, Y.Shimcmura and M.Kiritani, J.Nucl.Mat. 133 \& 131 (1985) 395 .

[10] M.I.Jenkins, C.A.English and B.I..Eyre, Phil.Mag. 38 (1978) 97.

[11] F.Häussermann, Phil.Mag. 25 (1972) 583.

[12] H.Föll and M.Wilkens, Phys.stat.So]. (a) 39 (1977) 561.

[13] W.J.Phythian, B.I.Eyre, D.J.Bacon and C.A.English, Phil.Mag. A.55 (1987) 757 .

[14] M.L.Jenkins and M.Wilkens, Phil.Mag 34 (1976) 1155.

[15] M.L.Jenkins and C.A.English, J.Nucl.Mat. $108 \& 109$ $(1982), 46$.

[16] T.J.Black, M.I.Jenkins, C.A.English and M.A.Kirk, Proc.Roy. SCC. A409 (1987) 177 .

[17] C.A.English, Rad.Eff. and Defects in Solids 113 (1990) 15.

[18] C.A.English, B.I.Eyre and J.Summers, Phil.Mag 31 (1976) 603 .

[19] C.A.English, B.I.EYre, A.F.Bartlett and H.N.G.Wadley, Phil.Mag. 35 (1977) 533 .

[20] A.Y.Stathopoulos, C.A.English, B.I.Eyre and P.B.Hirsch, Phil.Mag. 44 (1981) 309 . 
[21] C.A.English, B.I.Eyre, K.Shoaib and T.M.Williams, J.Nucl.Mat. 58 (1975) 220 .

[22] T.D.de la Rubia and W.J.Phythian, Proc. of 5th Int.ConE. on Fusion Reactor Materials, ICERM 5 ;J.Nucl.Mat.(1992)-to be published.

[23] M.W.Guinan, J.Nucl.Mat. (1992)-this issue.

[24] T.D. de la Rubia, R.S.Averback, R.Benedek and W.E.King, Phys.Rev.Lett. 59 (1987) 1930.

[25] R.S.Averback, T.D. de la Rubia, and R.Benedek, Nucl.Ins=r. and Methods, B33 (1988) 693.

[26] T,D. de la Rubia, K.Smalinskas, R.S.Averback, I.M.Roser=son and R.Benedek, Mat.Sci. Soc.Symp. Proc. 138 (1989) 29.

[27] T.D. de la Rubia, R.S.Averback, H.Hsieh and R.Beneisk, J.Mater.Res $\underline{4}$ (1989) 579 .

[28] T.D. de la Rubia and M.W.Guinan, Phys.Rev.Lett. 67 (1991)

[29] C.A.English, A.J.E.Foreman, W.J.Phythian, D.J.Bacon and M.I.Jenkins, Proc.Int. Conj. on Physics of Irracijeion Effects in Metals, Siofok, Fungarl, 1991: to be puidisied in Mat.Sci.Forum (1992)

[30] A.J.E.Foreman, C.A.English and W, J.Phytizian, AEA TechnclogI Harwell report AEA -TRS-2028 (1991)-submitted for publication.

[31] A.F.Calder and D.J.Bacon, Proc. of IEA workshop on the use of molecular dynamics in modelling irradiation efiects and other non-ecuilibrium phenomena, Ed. M.W.Guinan, Ia Jolla, CA, 1991; Rad.Eff.and Def.Solids (1992)-in press.

[32] A.J.E.Foreman, W.J.Phythian and C.A.English, AEA Technciogy Harwell report AEA-TRS-2031 (1991)- accepted For publication in Phil.Mag. (1992).

[33] M.A.Kirk, T.H. Blewitt and T.L.Scott, J.Nucl.Mat. 67-70 (1978) 780 .

[34] T.J.Bullough, C.A.Englisi and B.I.Eyre, Proc.Roy.Soc. (1992) in press

[35] V.J.Chudinov, B.N.Gishchitskii, N.V.Moseev and V.V.Andreev, Phys.stat.sol.(a) 119 (1.990) 437.

[36] V.G.Kapinos, Yu.N.Osetskii and P.A.Platanov, J.Nucl.Mat. $173(1990) 229$.

[37] I.M.Robertson, J.S.Vetrano, M.A.Kirk and M.I.Jenkins, Phil.Mag. A63 (1991) 299. 
[38] J.S.Vetrano, I.M.Roberson and M.A.Kirk, Scripta.Met. 24 (1990) 157.

[39] J.S.Vetrano, M.W.Bench, I.M.Robertson and M.A.Kirk, Met.Trans. 20A (1989)' 2673 .

[40] J.S.Vetrano, I.M.Robertson and M.A.Kirk, J.Nucl.Mat. (1992) - this volume.

[41] C.A.English, W.J.Phythian and A.J.E.Foreman, J.Nucl.Mat. 174 (1990) 135 .

[42] A.J.E.Foreman, and W.J.Phythian, AEA Technolog! Faz"iel] report A.EA-RS-2172 (1992)

[43] W.Jäger and K.L.Merkle, Phil.Mag. A57 (1988) 479.

[44] A.F.Calder, D.J.Bacon, W.J.Phythian and C.A.English, Proc. Conf. on Physics of Irradiation Effects in Metals, Siojok, Hungary, 1991: to be published in Mat. Science.Forum. (1992)

[45] N.Sekimura, Y.Yamanaka and S.Ishino, Proc. oE 15th Int. Symp. on Effects of Irradiation on Metals, Nashville, 1990: ASTM-STP (1992) to be published.

[46] H.Sadaida, N.Sekimura and S.Ishino, J.Nucl.Mat. 179-181 (1991) 928 .

[47] T.X.Bui, E.Sirois, I.M.Rcicertson and M.A.zirk, Prac. c $15=2$ Int.Symp. on EEjects of Irradiation cn Metels, Nashvilie, 1990: ASTM-STP (1992) to be published.

[48] W.J.Phythian, B.L.EYre and D.J.Bacon, J.Nucl.Mat.155157 (1988) $319^{\prime}$.

[49] W.J.Phythian, C.A.English, D.J.Bacon and B.I.Eyre, Phil.Mag. A.62 (1990) 617 .

[50] W.J.Phythian, C.A.English, D.H.Yellen and D.J.Bacon, Fhil. Mag. A63 (1991) 821.

[51] D.H.Yellen, D.J.Bacon, W.J.Phythian and C.A.English, Proc. 15th Int.Symp. on Radiation Effects in Solids, Nashville, 1990, ASTM-STP (1992) to be published.

[52] K.Smalinskas, G.Chen, I.M.Robertson and M.A.Kirk, J.Nucl.Mat. (1992) - this issue.

[53] J.S.Vetrano, I.M.Robertson and M.A.Kirk, submitted to Phil. Mag. (1992)

[54] D.K.Tappin, Ph.D. thesis, University of Iiverpool (1991)

[55] D.K.Tappin, D.J.Bacon, C.A.English and W.J.Phythian, Harwell Report AEA-TRS-2007 (1990); see also . . Nucl.Mat. (1992)-this issue. 
[56] S-J Kim, M-A Nicolet, R.S.Averback and D.Peak, Phys.Rev. B37 (1988) 38 .

[57] C.P.Flynn and R.S.Averback, Phys.Rev. B38 (1989) 7118.

[58] A.M.Stoneham, Nucl.Inst. and Methods B48 (1990) 389.

[59] M.W.Finnis, P.Agnew and A.J.E.Foreman, Phys.Rev.B 44 (1991) 567 .

[60] A.Caro and M.Victoria, Fhys.Rev.A 40 (1989) 2287.

[61] Y.Shimomura, M.W.Guinan, H.Fukushima, P.A.Hahn and Kiritani, J.Nucl.Mat. 155-157 (1988) 1181.

[62] M.O.Ruault, H.Bernas and J.Chaumont, Phil.Mag. A39 (1979) 757 .

[63] H.Fukushima, Y.Shimomura and H.Yoshida, J.Nucl.Mat. 179-181 (1991) 939.

[64] F.Häussermann, Phil.Mag. 25 (1972) 561.

[65] M.M.Wilson, Phil.Mag. 24 (1971) 1023.

[66] W.Gruschel, Dr.rer.nat.Thesis, University of stuttgart (1979)

[67] W.Sigle, M.I.Jenkins and J.L.Hutchison, Phil.Mag.LetE. $\underline{57}$ (1988) 267 .

[68] S.Kojima, Y.Satoh, T.Yoshii, H.Taoka and M.Kiritani, Phil.Mag. A59 (1989) 519. 
Table 1

Recent data on vacancy loop formation in some pure metals

\begin{tabular}{|c|c|c|c|c|c|c|}
\hline Metal & Ion & $\begin{array}{c}\text { Energy } \\
(\mathrm{keV})\end{array}$ & $\begin{array}{l}\text { Irradiation } \\
\text { temp. }(\mathrm{K})\end{array}$ & $\begin{array}{c}\text { Defect yield } \\
Y \\
\end{array}$ & $\begin{array}{c}\text { Cascade } \\
\text { efficiency } \varepsilon\end{array}$ & Ref. \\
\hline $\mathrm{Ni}$ & $\mathrm{Kr}^{+}$ & $\begin{array}{r}50 \\
50 \\
100 \\
\\
50 \\
50 \\
\end{array}$ & $\begin{array}{r}30 \\
300 \\
300 \\
\\
30 \\
300 \\
\end{array}$ & $\begin{array}{l}0.05 \pm 0.01 \\
0.14 \pm 0.01 \\
0.07 \pm 0.01 \\
0.12 \pm 0.01 \\
0.21 \pm 0.02\end{array}$ & & {$[37]$} \\
\hline $\mathrm{Au}$ & $\begin{array}{l}\mathrm{Bi}^{+} \\
\mathrm{Bi}_{2}{ }^{+}\end{array}$ & $\begin{array}{l}10 \\
20 \\
20 \\
40 \\
\end{array}$ & $\begin{array}{l}300 \\
300 \\
300 \\
300\end{array}$ & $\begin{array}{l}0.25 \\
0.33 \\
0.5 \\
0.73 \\
\end{array}$ & & {$[43]$} \\
\hline $\mathrm{Cu}$ & $\begin{array}{l}\mathrm{Bi}^{+} \\
\mathrm{Cu}^{+}\end{array}$ & $\begin{array}{l}10 \\
10 \\
10 \\
10 \\
\end{array}$ & $\begin{array}{r}4 \\
285 \\
4 \\
4 \\
285 \\
\end{array}$ & $\begin{array}{l}0.03 \\
0.05 \\
0.01 \\
0.07 \\
\end{array}$ & $\begin{array}{l}1.55 \\
1.27 \\
0.32 \\
0.59 \\
\end{array}$ & [44] \\
\hline $\mathrm{Fe}$ & $\mathrm{Fe}^{+}$ & $\begin{array}{r}50 \\
100 \\
100\end{array}$ & $\begin{array}{r}30 \\
30 \\
300\end{array}$ & $\begin{array}{l}\sim 0.001 \\
\sim 0.001 \\
\sim 0.001\end{array}$ & & {$[8,39]$} \\
\hline $\mathrm{V}$ & $W^{+}$ & 80 & 300 & $0.12 \pm 0.01$ & $0.20 \pm 0.05$ & {$[-1-8]$} \\
\hline $\mathrm{Ti}$ & $\mathrm{Sb}^{+}$ & $\begin{array}{l}100 \\
150\end{array}$ & $\begin{array}{l}300 \\
300\end{array}$ & $\begin{array}{l}0.07 \pm 0.02 \\
0.06 \pm 0.03\end{array}$ & $\begin{array}{l}0.19 \pm 0.02 \\
0.08 \pm 0.01\end{array}$ & {$[50]$} \\
\hline Co & $\mathrm{Sb}^{+}$ & $\begin{array}{l}100 \\
150\end{array}$ & $\begin{array}{l}300 \\
300\end{array}$ & $\begin{array}{l}0.14 \pm 0.04 \\
0.24 \pm 0.03\end{array}$ & $\begin{array}{l}0.51 \pm 0.03 \\
0.40 \pm 0.02\end{array}$ & \\
\hline$R u$ & $\mathrm{Sb}^{+}$ & $\begin{array}{l}100 \\
150\end{array}$ & $\begin{array}{l}300 \\
300\end{array}$ & $\begin{array}{l}0.36 \pm 0.07 \\
0.41 \pm 0.04\end{array}$ & $\begin{array}{l}0.24 \pm 0.01 \\
0.23 \pm 0.02\end{array}$ & \\
\hline $\mathrm{Re}$ & $\mathrm{Sb}^{+}$ & $\begin{array}{l}100 \\
150\end{array}$ & $\begin{array}{l}300 \\
300\end{array}$ & $\begin{array}{l}0.31 \pm 0.06 \\
0.36 \pm .0 .07\end{array}$ & $\begin{array}{l}0.18 \pm 0.01 \\
0.17 \pm 0.01\end{array}$ & \\
\hline $\mathrm{Mg}$ & $\mathrm{Sb}^{+}$ & 150 & 300 & $<0.01$ & & \\
\hline
\end{tabular}


Table 2

Recent data on vacancy loop formation in some alloys

\begin{tabular}{|c|c|c|c|c|c|c|}
\hline Alloy & Ion & $\begin{array}{c}\begin{array}{c}\text { Energy } \\
(\mathrm{keV})\end{array} \\
\end{array}$ & $\begin{array}{c}\text { Irradiation } \\
\text { temp. }(\mathrm{K})\end{array}$ & Defect yield $Y$ & $\begin{array}{c}\text { Cascade } \\
\text { efficiency } \\
\varepsilon \\
\end{array}$ & Ref. \\
\hline $\mathrm{Ni}$ & $\mathrm{Kr}^{+}$ & 50 & $\begin{array}{r}30 \\
300\end{array}$ & $\begin{array}{l}0.12 \pm 0.01 \\
0.21 \pm 0.02\end{array}$ & & [53] \\
\hline $\mathrm{Ni0.5at \% Al}$ & $"$ & $"$ & $\begin{array}{r}30 \\
300\end{array}$ & $\begin{array}{l}0.13 \pm 0.01 \\
0.34 \pm 0.01\end{array}$ & & \\
\hline $\mathrm{Ni0} .6 \mathrm{at} \% \mathrm{Al}$ & $"$ & $"$ & $\begin{array}{r}30 \\
300\end{array}$ & $\begin{array}{l}0.09 \pm 0.01 \\
0.23 \pm 0.01\end{array}$ & & \\
\hline $\mathrm{Ni5at} \% \mathrm{Al}$ & " & " & 30 & $0.07 \pm 0.01$ & & \\
\hline Ni4at\%Si & $"$ & $"$ & 30 & $0.06 \pm 0.01$ & & \\
\hline $15 \mathrm{Fe} 15 \mathrm{Cr} 70 \mathrm{Ni}$ & $\begin{array}{l}\mathrm{Bi}^{+} \\
" 1 \\
\mathrm{Xe}^{+} \\
\mathrm{W}^{+}\end{array}$ & $\begin{array}{r}20 \\
" \\
80 \\
80\end{array}$ & $\begin{array}{r}8 \\
300 \\
300 \\
300\end{array}$ & $\begin{array}{l}0.26 \pm 0.05 \\
0.45 \pm 0.05 \\
0.52 \pm 0.05 \\
0.53 \pm 0.05\end{array}$ & $\begin{array}{l}0.46 \\
0.52 \\
0.14 \\
0.17\end{array}$ & [54] \\
\hline
\end{tabular}


Table 3

Effects of low levels of impurities. Room temperature irradiations.

\begin{tabular}{|c|c|c|c|c|}
\hline Material & Ion & Energy & Defect yield & Ref. \\
\hline Al & $\mathrm{Kr}^{+}$ & 50 & $0.06 \pm 0.01$ & {$[47]$} \\
\hline Al-900appmH & & & $0.05 \pm 0.01$ & \\
\hline Al.1300ppmH & & & $0.04 \pm 0.01$ & \\
\hline \multirow[t]{9}{*}{ Ti-iodide purity* } & $\mathrm{Sb}^{+}$ & 50 & 0 & [51] \\
\hline & & 100 & 0.06 & \\
\hline & & 150 & 0.04 & \\
\hline & $\mathrm{Sb}_{2}+$ & 50 & 0.42 & \\
\hline & & 100 & 0.43 & \\
\hline & & 150 & 0.51 & \\
\hline & $\mathrm{Sb}_{3}+$ & 50 & 0.66 & \\
\hline & & 100 & 0.69 & \\
\hline & & 150 & 0.84 & \\
\hline \multirow[t]{6}{*}{ Ti-commercial purity* } & $\mathrm{Sb}^{+}$ & 50 & 0 & \\
\hline & & 100 & 0.07 & \\
\hline & & 150 & 0.06 & \\
\hline & $\mathrm{Sb}_{2}{ }^{+}$ & 150 & 0.67 & \\
\hline & $\mathrm{Sb}_{3}+$ & 100 & 0.77 & \\
\hline & & 150 & 1.01 & \\
\hline
\end{tabular}

* Orientation $S_{1}$, jields corrected for loop loss to surfaces. 


\section{Eigure captions}

Figure 1: "Cascade dissolution". Micrographs of the same area of a $\mathrm{Ni}$ specimen (a) irradiated at room-temperature with $100 \mathrm{kev}$ self-ions to a dose $3.4 \times 10^{16}$ ions $\mathrm{m}^{-2}$, and (b) after further irradiation to a total dose of 4.5 $x 10^{26}$ ions $\mathrm{m}^{-2}$. Loops marked with arrowheads are visible in (a) but absent in (b). After ref [37].

Figure 2: Molecular dynamics simulation of a $1 \mathrm{keV}$ cascade in "Cu" impinging upon a pre-existing 19-vacancy loop. The position of the primary event is marked with an loose cluster of vacancies is produced but no new loop forms. After ref [42].

Figure 3: Comparison of 100 p production as a function of dose in $\mathrm{Cu}, \mathrm{Ni}$ and $\mathrm{Fe}$ during $100 \mathrm{keV}$ self-ion irradiations at room-temperature. The slope of $n=1$ at low doses in $\mathrm{Ni}$ and $\mathrm{Cu}$ indicates cascade collapse at individual cacade sites. Note deviation from the $n=1$ lines at $\mathrm{high}$ doses due to overlap effects. Loops are formed in Fe cnly at high overlap doses. After ref [8].

Figure 4: Comparison of locp production as a function of dose in $\mathrm{Ni}$ and $\mathrm{Fe}$ during $50 \mathrm{reV}$ self-ion irradiations at $30 \mathrm{~K}$. Note the difference in slopes. After ref [8].

Figure 5: Defect yield in Ru as a function of ion energy for $\mathrm{Kr}^{+}$ ions (square symbols) and $\mathrm{W}^{+}$ions (diamond symbols). For either ion the yield increases with energy. However there is a reversal in the dependence of yield on ion mass on going from low to high ion energy. After ref [49].

Figure 6: Molecular dynamics simulations showing the effects of different electron-phonon coupling strengths on the evolution of a $500 \mathrm{eV}$ cascade in "Cu". Interstitials are shown as full squares and vacancies as open squares. The left-hand column shows the defect configuration 0.2 s after the primary event, whilst the right-hand column is after 7ps. The coupling strengths used correspond to (a) zero coupling, (b) Cu, (c) ten times $\mathrm{Cu}$ (or one-third $\mathrm{Ni}$ ), and (d) Ni. Note the large difference in remnant defects between (a) and (d). After ref [59]. 


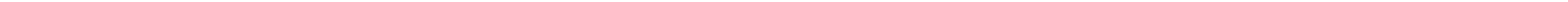



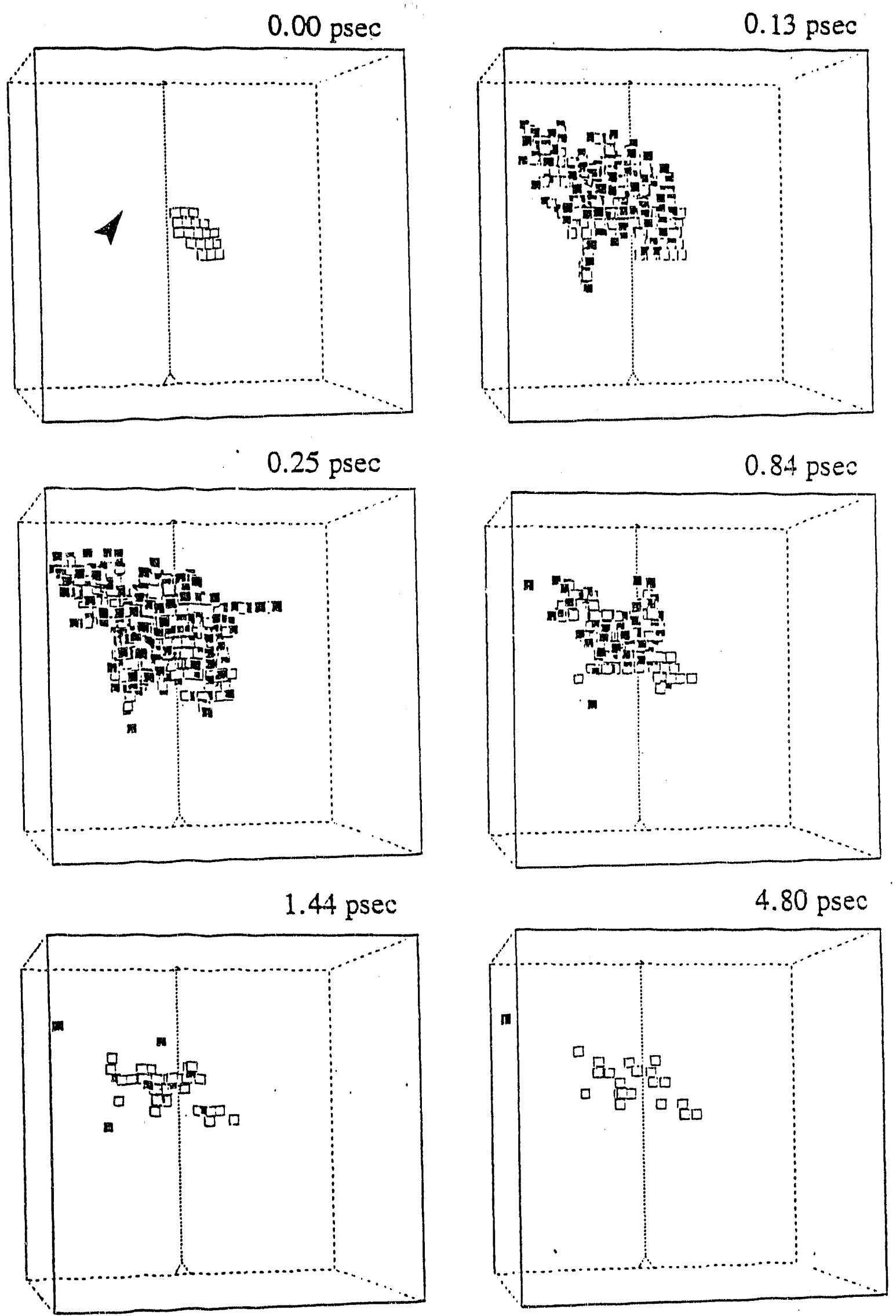

$1 \mathrm{keV}$ CASCADE

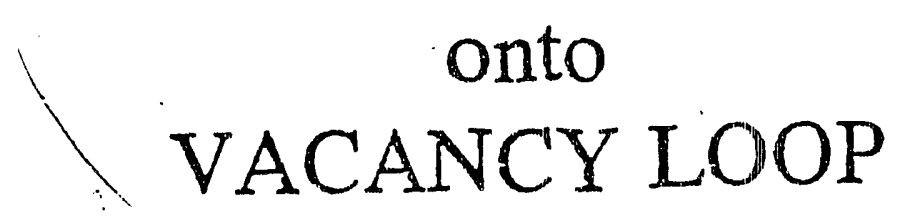




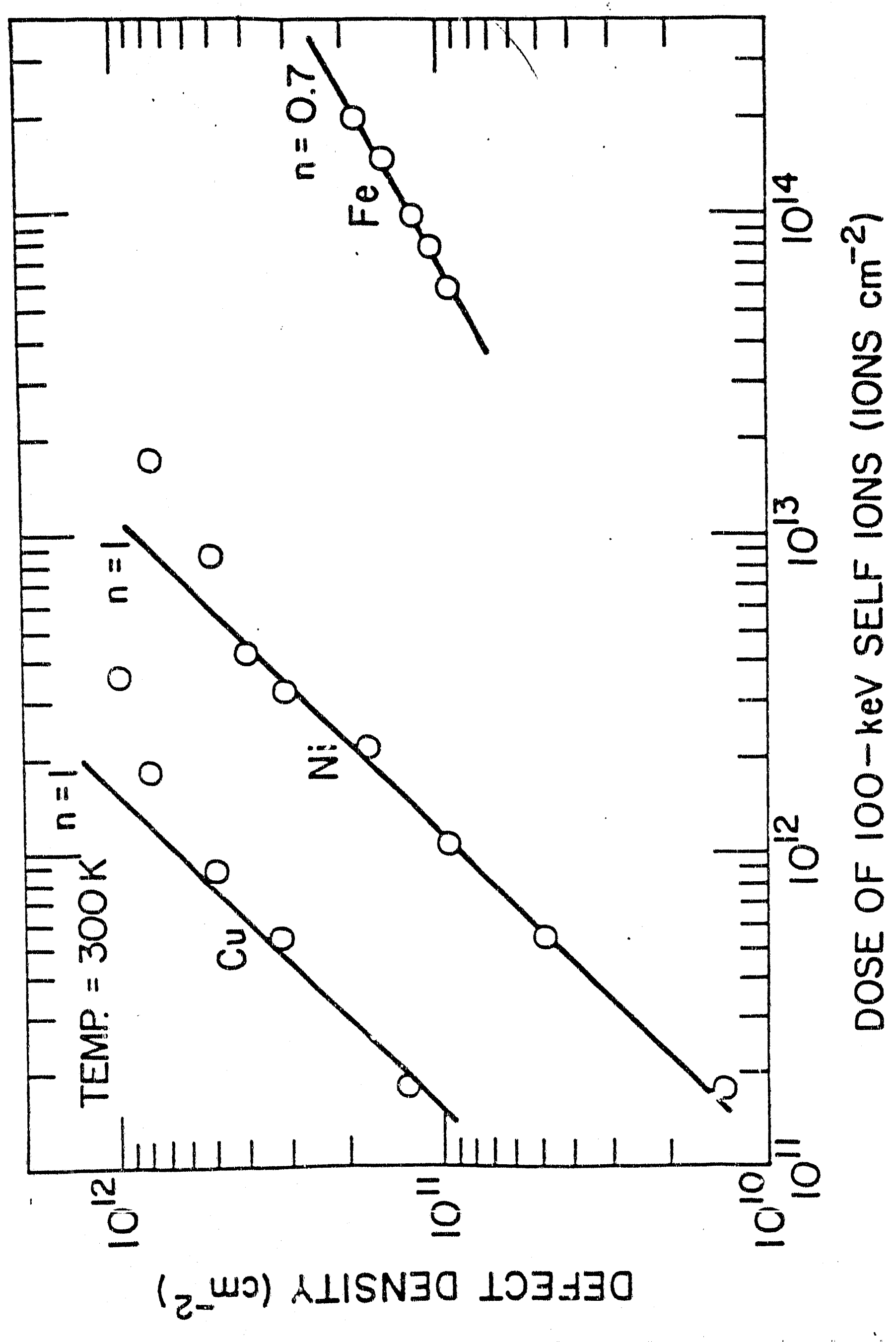




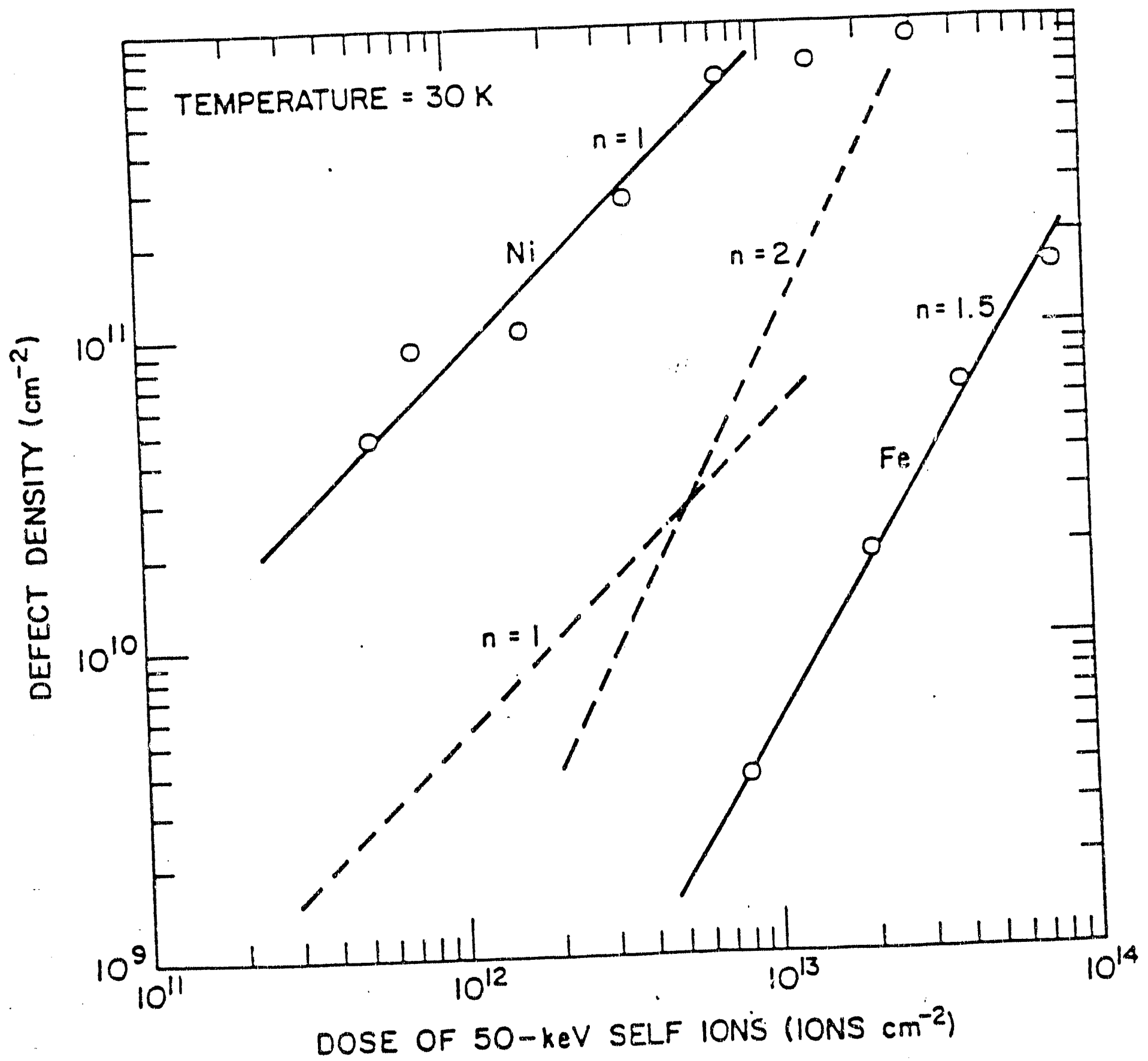




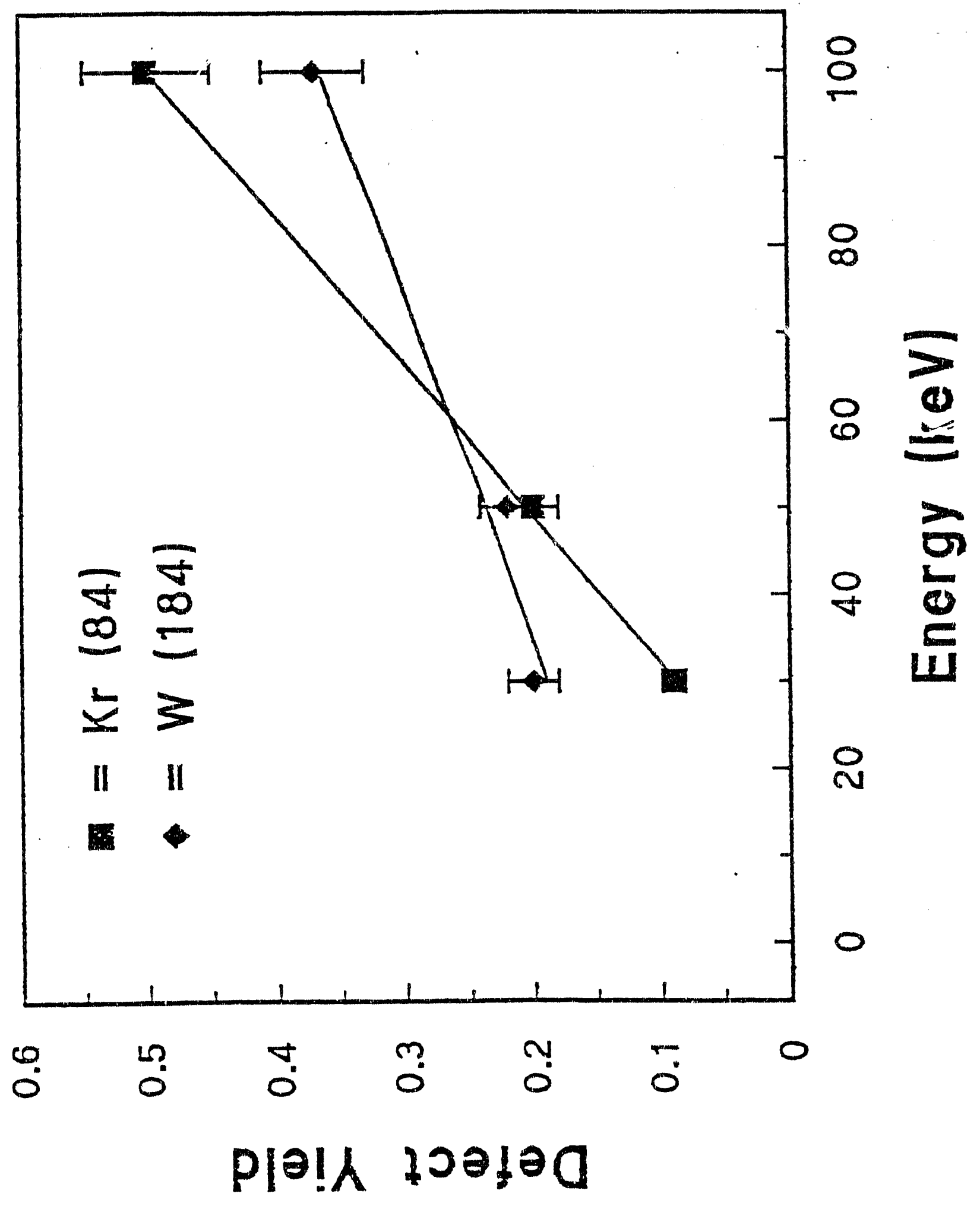



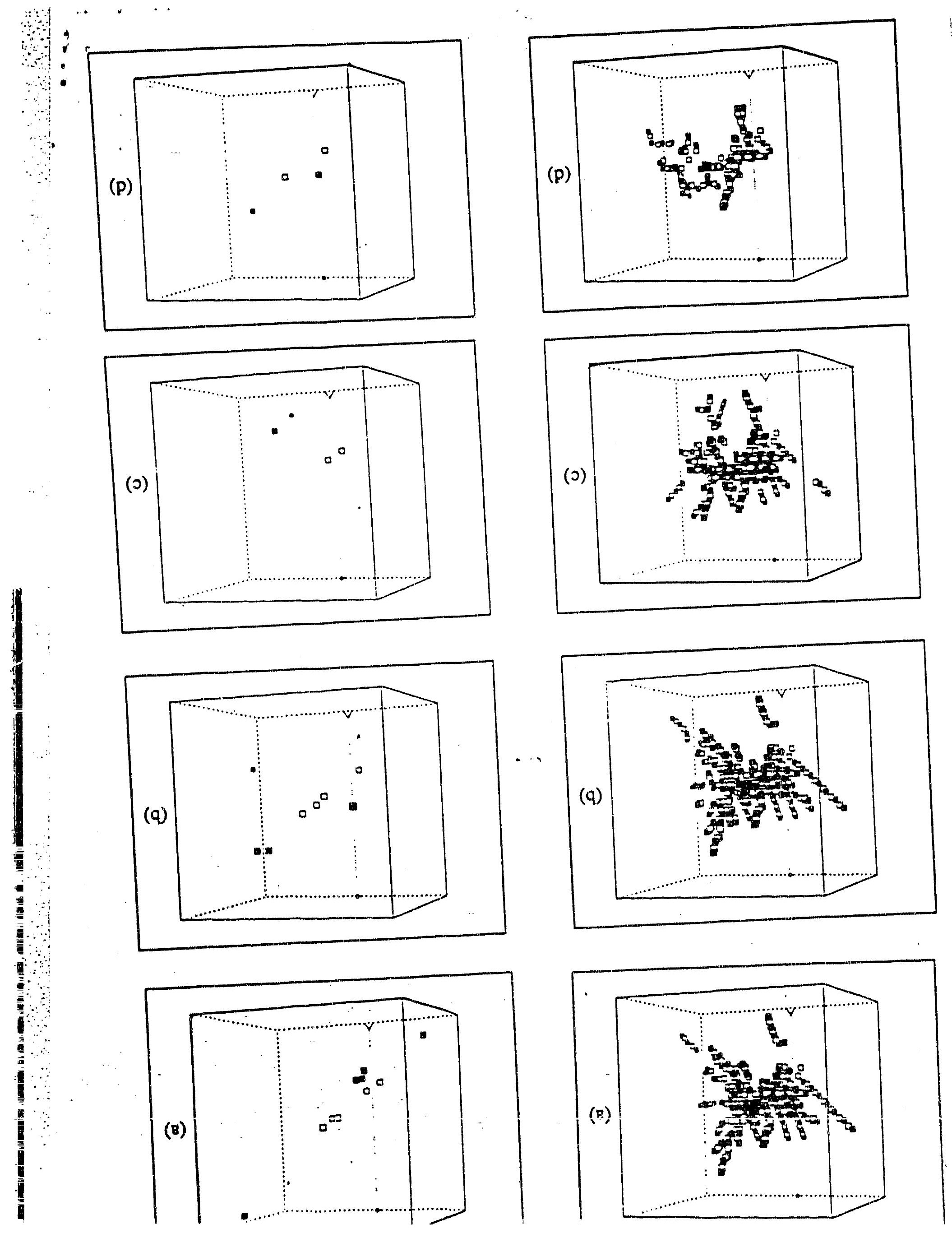

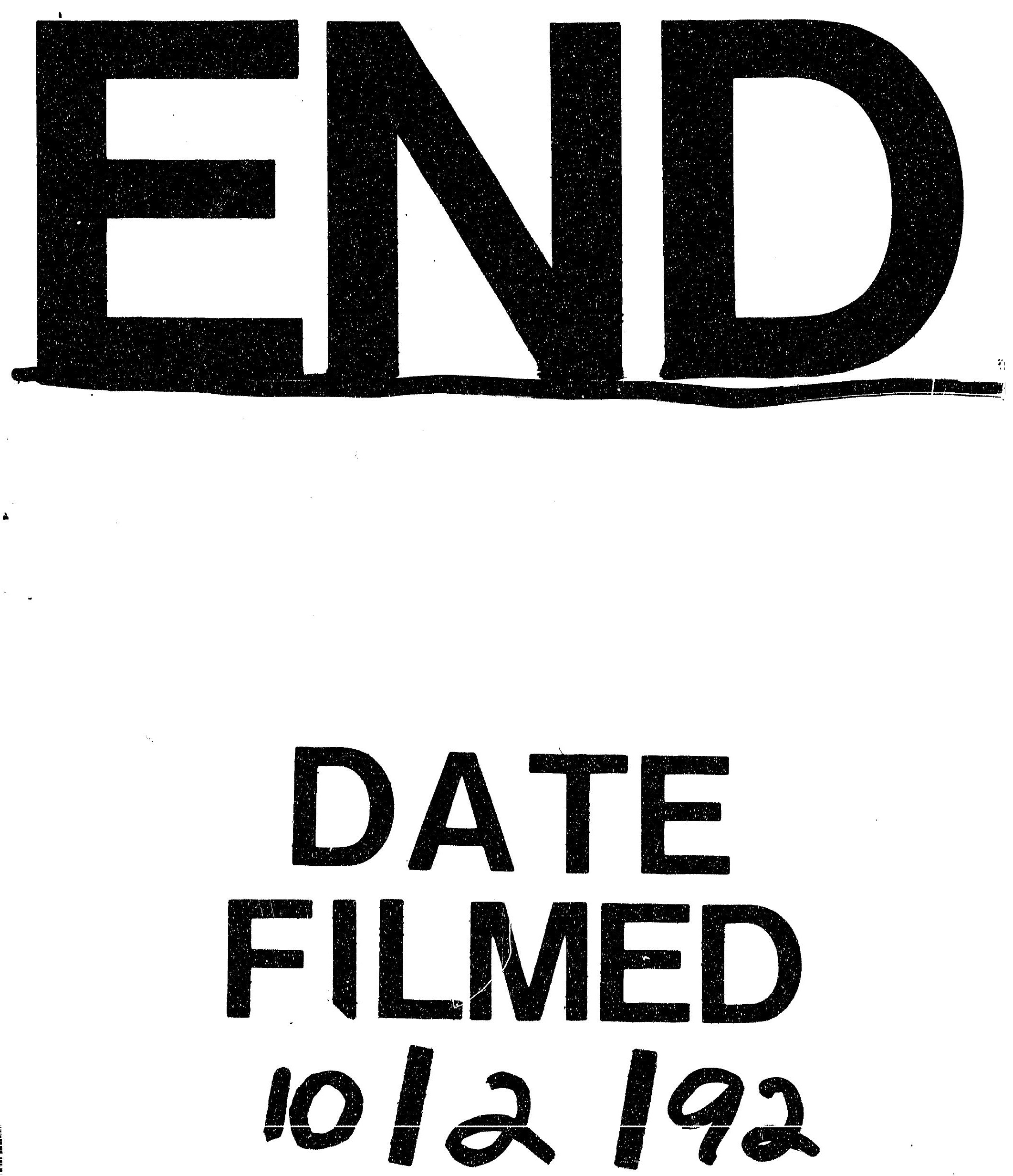

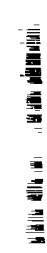


